\title{
Demandas discursivas regulatórias para "fazer a BNCC sair do papel" no Oeste da Bahia
}

\author{
Regulatory discursive demands to "make the base come out of paper" \\ in Western Bahia
}

\section{Demandas discursivas regulatorias para "sacar BNCC del papel" en el Oeste de Bahia}

\section{Clívio Pimentel Júnior ${ }^{1}$}

Universidade Federal do Oeste da Bahia, Centro das Ciências Biológicas e da Saúde, Professor assistente.

https://orcid.org/0000-0002-7544-4496

Resumo: Amparado nos estudos pós-fundacionais do currículo, defende-se a tese de que a política da Base Nacional Comum Curricular (BNCC), no Brasil, apesar dos esforços nacionais no âmbito dos estados e municípios para "fazê-la sair do papel", está fadada ao fracasso. Os materiais empíricos mobilizados neste texto fazem referência à itinerância acadêmica e profissional do autor na pesquisa em política de currículo, e envolve os seguintes registros e atores sociais: (i) depoimentos e planejamentos de ensino de professoras que "implementam", nos currículos escolares, as normas da BNCC; e (ii) escritas acerca da percepção de estudantes em vivência de estágio supervisionado, no que tange ao modo como a BNCC vem remodelando os currículos escolares da região e suas próprias atividades formativas. Argumenta-se que a BNCC está, incontornavelmente, sujeita aos processos disseminativos de interpretação, negociação e disputa de sentidos sobre o currículo e a própria educação que ocorrem no chão das escolas, desconfigurando-a em sua ânsia por transparência normativa e identidade fixa. Defende-se que, por mais que a BNCC e todos os discursos regulatórios a ela vinculados possam tentar "tirá-la do papel", ela continuará manifestando-se como uma orientação precária, finita, que permanece sendo tensionada e convidada ao diálogo com o outro por meio dos desajustes interpretativos, das readequações contextuais, enfim, por toda força criativa do diferir que esta julga poder estabilizar de uma vez por todas na educação.

Palavras-chave: Base Nacional Comum Curricular. Política de Currículo. Pós-estruturalismo.

Abstract: Supported by the post-foundational studies of the curriculum, it's defended the thesis that the policy of the National Curriculum Common Core (BNCC), in Brazil, despite the national efforts within the states and municipalities to "get it out of the paper", is doomed to failure. The empirical materials mobilized

Doutor e Mestre em Educação pela Universidade Federal da Bahia. 
in this text refer to academic and professional itinerancy of the author in curriculum policy research, and involve the following social actors and records: (i) testimonials and teaching plans of teachers who "implement" BNCC normative in school curricula; and (ii) written about the perception of students in supervised internship experience regarding the way the BNCC has been reshaping the school curricula of the region and your own formative activities. It's argued that the BNCC is unavoidably subject to the widespread processes of interpretation, negotiation and dispute over the curriculum and education itself that take place on the school floor, disfiguring it in its eagerness for normative transparency and fixed identity. It's defended that, as much as the BNCC and all its regulatory discourses may try to "get it of the paper", it will continue to manifest itself as a precarious and finite orientation, that remains tense and invited to dialogue with others through interpretive and contextual readjustments, in short, by all the creative force of differing that it thinks it can stabilize once and for all in education.

Keywords: National Curriculum Common Core. Curriculum Policy. Poststructuralism.

Resumen: Con el apoyo de los estudios curriculares post-fundacional, defiende la tesis de que la politica de la Base Nacional Curricular Común (BNCC) en Brasil, a pesar de los esfuerzos nacionales a nivel estatal y municipal para "sacarla del papel", está condenada al fracaso. Los materiales empíricos movilizados en este texto se refieren a itinerancia académica y profesional del autor en la investigación de politicas curriculares, e involucran a los siguientes actores y registros sociales: (i) testimonios y planes de enseñanza de maestros que "implementan" los estándares BNCC en los planes de estudio escolares; y (ii) escrito sobre la percepción de los estudiantes en pasantías supervisadas, sobre la forma en que el BNCC ha estado remodelando los planes de estudio de la región y sus propias actividades de capacitación. Se argumenta que el BNCC está inevitablemente sujeto a los procesos generalizados de interpretación, negociación y disputa sobre el plan de estudios y la educación en sí que tienen lugar en el piso de la escuela, lo que lo desfigura en su afán por la transparencia normativa y la identidad fija. Se argumenta que, por mucho que el BNCC y todos sus discursos regulatorios puedan tratar de "sácala del papel", continuará manifestándose como una orientación precaria y finita que permanece tensa e invitada a dialogar con otros, a través de desajustes interpretativos, reajustes contextuales, en resumen, por toda la fuerza creativa de diferencia que cree que puede estabilizarse de una vez por todas en la educación.

Palabras clave: Base de Currículo Nacional Común. Politica curricular. Post-estructuralismo.

Recebido em 14 de fevereiro de 2020

Aceito em 15 de maio 2020

Publicado em 24 de setembro de 2020 


\section{INTRODUÇÃO}

Meu foco, neste texto, é argumentar sobre o porquê de acreditar que a política da Base Nacional Comum Curricular (BNCC) está fadada ao fracasso. E está fadada ao fracasso, defendo, por ser uma busca vã por soluções antipolíticas para o currículo, baseada em um fundamento de como a educação e a identidade do outro devem ser para que seja possível atingir específicas finalidades educativas e de transformação social. Quando falo "baseada em um fundamento", refiro-me não apenas à ideia de fundamento, a qual desenvolvo a seguir, mas a uma longa tradição de estudos curriculares que tenta estabilizar a própria concepção do que vem a ser currículo, buscando fundá-lo em bases firmes, supostamente capazes de nos fazer pensar que não existem maneiras outras de pensá-lo e fazê-lo nos mais diversos espaços tempos educacionais, incluindo ai, sobretudo, os escolares. Trata-se de uma racionalidade que busca frear as disputas discursivas sobre o que vem a ser currículo e educação.

Questionar racionalidades fundacionistas de identidade para o social, a educação e o currículo, tem sido um propósito de trabalho perseguido por diversos autores no campo da política de currículo inspirados nos registros discursivos pós-fundacionais e pós-estruturais. Trata-se de trabalhos que se articulam mediante o antagonismo a perspectivas prescritivas de currículo, que comumente projetam sobre a educação, a escola e os sujeitos que engendram seu cotidiano, metas fixas de aprendizagem baseadas na ideia de conhecimento como coisa a ser possuída mediante socialização. A socialização seria a via pela qual a aquisição do conhecimento e as, subsequentes, mudanças de comportamentos pré-definidos poderiam ser mensuradas, lançando a educação no terreno do cálculo (BIESTA, 2013, 2016). De acordo com esses estudos, é justamente por estar radicada nesta concepção proprietária de conhecimento e prescritiva de identidade e de currículo, que a racionalidade fundacionista pode tratá-lo no espaço da previsibilidade, do controle e da suposta harmonia na transmissão consensual do sentido nas comunicações educativas.

Neste caminho de argumentação crítica a respeito da ânsia fundacionista na política de currículo, o trabalho de Frangella e Dias (2018), por exemplo, ao advogar em favor de uma concepção de currículo que o compreende como luta pela significação, nos dá a pensar em como o currículo é "uma produção político-discursiva nunca passível de totalização" (FRANGELLA; DIAS, 2018, p. 9). As autoras, baseadas em Laclau e Mouffe (2015), argumentam que toda configuração curricular é uma produção significativa, isto é, se dá no terreno do discurso que, por sua vez, é marcado pela ausência de um centro fixo único. Como não há centro único e nem fixação absoluta de sentido, toda e qualquer significação curricular é compreendida como um discurso que tenta suturar uma ordem, mas o faz de modo parcial e precário, marcado pela contingência que habita a decisão que a tornou possível. 
0 trabalho de Cunha (2015), ao problematizar como a ideia de uma unidade curricular essencial é um investimento interessado em ocultar as relações de poder que a sustenta, argumenta que as ações que envolvem a produção da BNCC são performatizações de uma angústia frente a um temido descontrole na educação, o que faz emergir forças políticas atuantes na instituição do currículo como totalidade a ser alcançada. Ao sintomatizar o controle da educação e do currículo como aquilo que falta para um ensino de qualidade nas escolas, a ideia de uma base, argumenta a autora, inscreve a educação na lógica do significado fixo (cultura e conhecimento fixos a serem partilhados), atualizando "a crença em um fundamento último como reparador dos problemas educacionais." (CUNHA, 2015, p. 577). Amparada em registro pós-estrutural do currículo e da cultura, Cunha (2015) vai argumentar, confrontando a lógica do cálculo, pela falibilidade de todo texto, incluindo aí o texto curricular, o que permite problematizar toda e qualquer ideia que advoga por uma unidade essencial para o currículo, lançando-nos aos imprevisíveis e irrefreáveis jogos de linguagem, que nos convocam a disputar qualquer significação, incluindo aí a educacional e a curricular.

Já no trabalho de Lopes (2015b), em uma radicalização da perspectiva pósfundacional, a autora, explorando como a proposta por uma BNCC foi apresentada em três propostas de governo nas eleições de 2014, argumenta por uma compreensão da política de currículo como um constante processo de tradução, o que pode levar a fracassar qualquer registro de conhecimento que se manifeste como tendo um selo oficial de verdade. Questionando esse registro fundacionista de conhecimento, a autora critica a ideia de que é possível alcançar um consenso curricular fora das múltiplas disputas contextuais, o que a leva a argumentar por um currículo sem fundamentos, isto é, sem uma base sólida que pudesse cessar a política e a tradução que o constituem. Já em outro texto, Lopes (2015a) volta ao debate sobre o modo como a BNCC se coloca como racionalidade curricular essencial a todos, retomando a discussão sobre a disputa de regras e princípios curriculares, para defender a produtividade do que denomina de vazio normativo na política de currículo. Apostar em um vazio normativo, segundo Lopes, não significa deixar de planejar e fazer projetos e julgamentos sobre o currículo; antes, significa compreender que as normas não têm os "supostos alicerces epistemológicos sólidos, capazes de serem justificados fora da luta política que se remete às condições de existência de todos nós" (LOPES, 2015a, p. 140), levando a entender que a teoria e a política de currículo podem não ter uma função normativa forte de querer predizer o futuro e determinar identidades universais.

Macedo (2014) contribui decisivamente para o debate ao mapear os agentes públicos e privados envolvidos na hegemonização do discurso por uma BNCC no Brasil. De acordo com ela, as redes de sociabilidade e de demandas dos sujeitos políticos públicos e privados que giram em torno da ideia de uma base curricular, sempre produzidas em nome da qualidade da educação e contra uma crise - em alguma medida, fantasiosa -, vêm produzindo diferentes formas de regulação do currículo e da prática docente. Essas redes, de acordo com 
a autora, partem da ideia de que, agindo de acordo com as orientações curriculares explícitas sobre o que ensinar e aprender mediante padrões nacionais, será possível controlar o que acontece no chão da escola. Com isso, Macedo (2014) argumenta que as formas de regulação visam expulsar da educação o imponderável - isto é, aquele ingovernável e inapreensível processo de produzir sentidos na relação educativa -, que precisa ser, constantemente, controlado, para que a hegemonia em torno da ideia de Base Curricular - e sua promessa de qualidade garantida - se mantenham firmes, como única saída, no horizonte das políticas curriculares. Ao ler o texto da autora, é possível perguntar: a que nível/tipo de relação precisaremos reduzir a educação para que ela se mostre como algo que "funcione"? Que jogos e articulações políticas vêm produzindo uma linguagem para a educação como aquilo que "precisa funcionar'? 0 que perdemos ao tentar controlar a insegurança, o inesperado, aquilo mesmo que emerge, de modo mais ou menos imprevisível, nas relações educativas? Não estaria a ideia de "funcionar" reduzindo a educação à uma noção de cálculo preciso entre o input e o output nas relações de ensino e aprendizagem? (BIESTA, 2013).

Há, portanto, uma profusão de narrativas curriculares acadêmicas contemporâneas implicadas na problematização de diversos aspectos em torno da ideia de uma Base Comum Curricular, mostrando a contingência e os jogos de poder que configuram a emergência desta racionalidade curricular no Brasil, questionando, sobretudo, sua suposta essencialidade para alcançar uma educação de qualidade. Procurando inserir-me no fluxo desses estudos discursivos, focalizo, neste texto, o modo como a racionalidade fundacionista, que sustenta o imaginário de um currículo único garantidor de uma educação de qualidade no âmbito de todos os Estados e Municípios brasileiros mediante a BNCC, está fadada ao fracasso. Meus argumentos seguem um sentido reiterativo no que diz respeito às diversas defesas teóricas em torno da impossibilidade de uma base curricular comum, amplificando a luta política em torno da defesa de sua ineficiência centralizadora para fazer face aos desafios educacionais brasileiros. Ao trazer a ideia de "fadado ao fracasso", refiro-me, especificamente, ao fracasso em impedir que a normatividade curricular que ela põe em curso seja submetida às leituras e à interpretação nos mais variados contextos educacionais para os quais ela, enquanto universal, está sendo endereçada, isto é, aos inúmeros processos relacionais de negociação de sentidos que, incontornavelmente, estão implicados no processo de "fazer a BNCC virar realidade" (MACEDO, 2019). Acredito, com Butler, que "cada instância normativa é acompanhada de perto por seu próprio fracasso" (BUTLER, 2017, p. 22) e que, por este motivo, estão sujeitas, no diálogo com o outro em uma relacionalidade incontornável, ao desfazimento de qualquer princípio de identidade fundado como um próprio, um construto estável (BUTLER, 2015). Nesta direção, questiono a projeção normativa e o universalismo da BNCC, supostamente imune ao diferir, mobilizando, estrategicamente, materiais empíricos diversos que nos permitem pensar, defendo, em como a BNCC vai sendo (des)feita nos contextos educacionais. 
Para tanto, focalizo, inicialmente, as discussões sobre a educação e a política de currículo na pauta pós-estrutural e pós-fundacional, fazendo emergir a compreensão de que o currículo está irredutivelmente sujeito aos processos de disputas discursivas pela sua significação, extraindo-o de uma concepção teleológica tida como fundamental e obrigatória. Em seguida, ainda nesta seção, discorro sobre algumas questões metodológicas a respeito da mobilização dos materiais empíricos elencados para este trabalho. Posteriormente, problematizo o que vem sendo denominado "fase de implementação" da BNCC em escolas estaduais e municipais de Barreiras, Bahia, situadas na região Oeste do Estado, compondo argumentos em diálogo com os materiais empíricos mobilizados. Neste momento, discuto o modo como esta etapa da política parece instaurar certa ambiência regulatória no âmbito das escolas, engendrada pelos movimentos de estudos e tentativas de "aplicação" das normas da BNCC no currículo, envolvendo esforços de todos nesta tarefa. Por fim, defendo que a BNCC, apesar dos esforços que mobiliza em múltiplas escalas de ação visando torná-la regra absoluta no currículo, está fadada ao fracasso, posto que incapaz de homogeneizar e fixar, de uma vez por todas, a identidade do currículo, do outro e da educação em sua singularidade.

\title{
2 A POLÍTICA DE CURRÍCULO PÓS-FUNDACIONAL: ESTUDOS DISCURSIUOS
}

\begin{abstract}
A categoria central aqui é a de Abgrund - um fundamento que é, por sua vez, um abismo. No lugar do fundamento, há um abismo - ou, para ser mais preciso, o abismo mesmo é o fundamento. Dizer que o abismo mesmo é o fundamento não significa, pura e simplesmente, a ausência de fundamento, que seria uma ausência apenas, mas, senão, a presença de uma ausência. E esta ausência, enquanto presença, precisa ser representada. [... Esta representação não pode, porém, ser direta porque o que é representado é uma ausência. [...] Sendo que não há fundamento último, não há também fixação última de sentido; mas porque este momento de não fixação deve ser representado, ele abre o caminho para fixações parciais - quer dizer, a fixações que mostram os traços da contingência que a penetra, e que são o único meio de mostrar discursivamente o abismo presente no lugar do fundamento. (LACLAU, 2014, p. 146).
\end{abstract}

De início, como o trecho acima sugere, destaco que operar na pauta pósfundacional, a partir da teoria do discurso de Laclau e Mouffe (2015), não significa abandonar toda e qualquer possibilidade de fundamento, mas entendê-lo como constitutivamente penetrado pelos traços da contingência, o que o torna uma construção falível, precária, sujeita a disputa. Na perspectiva pós-fundacional com a qual venho trabalhando em minhas pesquisas, aceita-se a possibilidade de algum fundamento contingente assumir o espaço da 
representação; assume-se apenas que essa representação não se configura como uma obrigatoriedade sistêmica, uma destino manifesto, uma necessidade obrigatória, a tal ponto de ser tomada como um centro, a própria plenitude presente. Tampouco ela precisa assumir o espaço da representação na forma de um dever ser, isto é, na forma de uma exigência identitária supostamente essencial a todos.

Outro aspecto a destacar desta abordagem diz respeito à ideia de que a representação de um universal, ou de uma identidade coletiva, manifesta, compulsoriamente em sua estrutura, uma ausência. Isso implica dizer que qualquer discurso que emerge com uma função de fixação provisória no horizonte social nada mais é que um particular que foi destacado por relações de poder e articulações políticas específicas, em determinadas redes de sociabilidade (LACLAU, 2014; LACLAU; MOUFFE, 2015). Na teoria do discurso, esses atos de instituição representativa, que são sempre marcados pela contingência, emergem sendo tensionados por identidades que foram excluídas do processo de articulação política que hegemonizou uma determinada particularidade ao espaço da representação. Isso significa o mesmo que dizer que a representação só "tem lugar em um campo cercado pela presença de forças antagônicas" (LACLAU, 2014, p. 151), mostrando que a representação nunca é uma construção absolutamente universal, tampouco é capaz de totalizar o social.

Assumir, portanto, que a presença do fundamento só se manifesta enquanto ausência, enquanto falta, e que a função de representação é dada por um particular despossuído de qualquer positividade plena e alçado à esta condição, implica aceitar que qualquer construção discursiva precisa disputar com outras tantas a sua condição de representatividade, o que torna a dimensão política uma marca ontológica de todo discurso interessado em produzir uma representação. É desta forma que, na perspectiva discursiva pós-fundacional, a representação hegemônica é entendida como uma operação na qual uma concepção particular foi alçada a uma universalidade, adquirindo a função de centralizar esforços e investimentos políticos em uma dada direção que não é, em nada, reforço, um destino obrigatório a todos.

No pensamento de Vattimo $(1980,2007)$, encontramos aspectos característicos de como a racionalidade fundacionista se manifesta. Para ele, o pensamento do fundamento concentra-se na tentativa de manifestação da presença, na manifestação de uma plenitude identitária, de um signo fixo, de uma objetividade final, que pudesse estancar os processos de diferenciação - da identidade, da significação -, ou, ao menos, controlá-los como referência primordial. Pensar distante do fundamento, para Vattimo (2007), significa aceitar a dissolução de grandes categorias do pensamento moderno, incluindo aí, a ânsia pela estabilidade, a ânsia pela presença, a ânsia por conferir um sentido final à história, a ânsia pela origem, enfim, a ânsia por encontrar um pensamento que valha como referência de verdade. 0 fundamento só se manifesta, em sua concepção, como uma estabilidade fraca, como uma intuição precária, 
ressignificando, desta forma, a própria ideia de realidade, retirando-a da mesmidade fixa e apresentando-a em uma diversidade de cores, enigmas, significados.

A partir desses aspectos, podemos entender que a abordagem pós-fundacional seria, portanto, uma tentativa de abandono do pensamento da presença, da tentativa de estabelecer certezas e verdades absolutas manifestadas a partir de crenças que se querem fora do tempo, do espaço e do acaso de sua constituição. Trata-se da tentativa de abandono de crenças e ideais que buscam ocultar as contingências e os jogos de poder que as sustentam como se houvesse um momento no qual tais crenças e ideais pudessem desligarse de todas as intuições e decisões que as fizeram emergir de específicas maneiras no mundo.

Em muitos aspectos e em muitas perspectivas, o campo do currículo é, ainda, marcado por traços normativos fundacionistas, dentre os quais, podemos citar: (i) a busca por critérios e pela seleção do conhecimento mais importante na formação, (ii) a busca por fixar molduras identitárias projetadas como necessárias à toda sociedade, (iii) a busca por tentar projetar a identidade do outro no tempo e no espaço, (iv) a busca teleológica por transformações sociais mediante projetos fixos, (v) a compreensão da educação como um empreendimento de socialização e reconhecimento, (vi) a responsabilização do professor por produzir ou manifestar alguma coisa no sujeito, entre outros (LOPES; MACED0, 2011; BIESTA, 2012, 2013). Essas características encontram-se conectadas por uma dada concepção normativa de currículo e educação que a concebem como atividade formadora de identidades. A questão com a normatividade, como afirma Biesta (2013), é que ela cria uma norma prévia acerca do que significa ser educado, excluindo outras possibilidades de o sujeito vir ao mundo. 0 campo do currículo reatualiza, constantemente, esses traços em suas teorizações, manifestando uma ânsia por suprir aquilo mesmo que pode ser constitutivo da educação e do social: a plenitude ausente. É por haver grandes apostas nesse imaginário educacional, que muitas teorizações fundacionistas permanecem hegemônicas por longos períodos históricos, nos fazendo pensar que não há como abandonar certas crenças e premissas educacionais.

A abordagem pós-fundacional, nesse sentido, vem permitindo a construção de caminhos investigativos capazes de questionar até mesmo premissas centrais de teorias curriculares hegemônicas e fortemente estabelecidas, mostrando que seu processo de sedimentação no imaginário social é uma construção baseada em decisões contingentes que podem ser reativadas. ${ }^{2}$ Assim, nessa abordagem, toda ideia que se apresenta como natural, toda racionalidade que se apresenta como obrigatória, como uma necessidade 
universal, passa a ser compreendida como uma intuição forjada por decisões possiviseis em um específico contexto social.

Na pauta pós-fundacional, a ideia de reativar hegemonias tem sido potente pra enfraquecer discursos educacionais altamente normativos, na medida em que se torna possível amplificar os antagonismos e mostrar as exclusões constitutivas. Reativar discursos, em meus estudos, tem se tornado uma estratégia investigativa utilizada com vistas a argumentar que, daquelas intuições originárias que forjaram uma determinada decisão política, poderia não vir aquilo que, de fato, veio e que se apresenta como obrigatório. Nenhuma base de fundamentação, portanto, que participou das decisões que foram tomadas a respeito da BNCC é inquestionável e/ou determinou, de uma vez por todas, esse caminho específico no cenário da política de currículo nacional; algo diferente poderia ter emergido e vindo a manifestarse naquele mesmo cenário, mas teve sua atualização bloqueada pelas articulações que viabilizaram a centralização da política de currículo via BNCC.

Para o campo da educação e do currículo, as perspectivas pós-fundacionais vêm permitindo, também, a crítica aos determinismos e fundamentos fixos que, invariavelmente, sustentam perspectivas pedagógicas baseadas na defesa do que é essencial para todos. Em uma visada pós-fundacional, dizer o que é essencial para todos pode ser entendido como uma operação do poder implicada em produzir normas do que seja uma identidade fundamental, manifestando uma relação de controle que credencia pensar na produção de versões autorizadas da alteridade (BHABHA, 2013), condenando o emergir da diferença.

Com isso, a abordagem pós-fundacional mostra toda sua potencialidade para pensar a política de currículo: não há registro epistemológico, político ou pedagógico algum que determine, de uma vez por todas, que a intuição por uma BNCC seja o caminho de maior garantia de qualificar a educação. Não há um destino manifesto, portanto, em nenhum desses registros que possa fundamentar e direcionar os esforços políticos nessa direção, como se fosse um caminho obrigatório, essencial a todos, a única forma de alcançar a justiça social e a qualidade na educação. Não apenas isto, a perspectiva discursiva pósfundacional permite questionar também a busca metafísica de soluções genéricas para a educação mediante políticas centralizadas de currículo, na medida em que permite questionar os discursos baseados nas ideias falta, crise, ausência, entre outros, de transparência e qualidade na educação e na política, enfraquecendo, portanto, a própria estratégia que atua hegemonizando discursos pró-centralidade curricular como o da BNCC.

Pondero, nessa direção, que a BNCC, ao buscar definir o essencial, aquilo que considera o fundamento curricular obrigatório a todos, na busca por enfrentar o que julga ser deficitário e de baixa qualidade na educação, manifesta uma política de identidade fundacionista que só poderá servir para fins de cálculo, regulação e controle da educação. Em uma visada pós-fundacional, ela pode ser entendida como sendo parte de estratégias fundacionistas que 
tentam definir bases seguras e certezas tranquilizadoras para a educação, transformando-as em parâmetros de controle da docência. No contexto da BNCC, isso vem significando tentar tornar a educação um empreendimento plenamente mensurável a partir de políticas de identidade baseadas em competências e habilidades previamente definidas, o que pode reduzir a educação a adaptação / socialização, extirpando a própria singularidade (BIESTA, 2013).

Em última análise, a perspectiva discursiva pós-fundacional vem provocando certa angústia na cena da teorização curricular ao colocar em xeque e em disputa política, crenças fortemente sedimentadas como nosso apego fantasmático ${ }^{3}$ à cultura do Esclarecimento na educação, e à busca por critérios de seleção de conhecimentos capazes de realizar tal projeto formativo. Expondo a educação e a política de currículo à vertigem do abismo, essa perspectiva teórica parece vir tentando forjar linguagens educativas que buscam permitir, àquele que chega, um acolhimento sem reserva, porque, agora, talvez, com menos cálculos e menos certezas acerca do que poderá, ou não, emergir nas relações educativas.

\subsection{ALGUNS ASPECTOS METODOLÓGICOS ACERCA DESTE POSICIONAMENTO}

Em pauta pós-fundacional, mobilizar materiais empíricos buscando defender que o princípio único de identidade curricular posto em marcha pela BNCC está fadado ao fracasso pode ser uma operação arriscada. Arriscada, pois, esse caminho poderia levar-me a uma trama realista ${ }^{4}$ no trabalho. Essa trama poderia ser interpretada como uma argumentação simples que opõe o caráter universal da política da BNCC e os registros de como o currículo e as negociações de sentido sobre ele, de fato, acontecem nos contextos. Ou seja, defender o desfazimento do princípio de identidade universalista da BNCC, de como seu universalismo sucumbe, tomando como base uma perspectiva etnocêntrica de sentidos contextuais, me colocaria em terreno também fundacionista. Não foi essa a minha intenção aqui.

0 intuito de lastrear a defesa da tese aqui sustentada mediante a mobilização de materiais empíricos diversos é apenas de fazê-los trabalhar em uma argumentação crítica a respeito da BNCC. Em acordo com Lopes (2018), acredito que lançar mão de registros empíricos não significa, nesta abordagem, uma prova irrefutável daquilo que se busca defender,

3 De acordo com Glynos e Howarth (2008), a lógica fantasmática permite entender o porquê de práticas discursivas subjetivarem sujeitos em modos específicos de estar junto. Não se trata, pois, de mera ilusão ou ideia fantasiosa em oposição a uma realidade dada, mas de fantasias constitutivas de identidades coletivas.

4 Refiro-me ao realismo científico que, de modo geral, pode ser caracterizado pela crença na ideia de que aquilo a que nos referimos por meio dos modelos e conceitos científicos são entidades dadas na natureza, dotadas de plenitude ontológica, independente dos vocabulários que mobilizamos para descrever esses processos. 
colocando a argumentação no terreno da linguagem e a pesquisa em um ambiente antirrealista, sem a possibilidade de amparo em um marco externo e fixo que pudesse ser tomado como campo referencial da verdade. Nesse sentido, o intuito foi operar uma agência desconstrutiva dos universalismos e identitarismos abstratos da BNCC, mediante a representação teóricoestratégica de como a normatividade que ela põe em marcha é incapaz de escapar às negociações contextuais e aos deslizamentos de sentidos nas interpretações.

Os materiais empíricos mobilizados neste trabalho foram: (i) depoimentos e planejamentos de ensino de professoras que "implementam", nos currículos escolares, as normas da BNCC; e (ii) escritas acerca da percepção de estudantes em vivência de estágio supervisionado, no que tange ao modo como a BNCC vem remodelando os currículos escolares da região e suas próprias atividades formativas. A escolha desses materiais se deu devido à minha relação direta com esses atores sociais na prática profissional. Justifica-se, também, pelo fato de que venho percebendo a formação de uma ambiência regulatória forjada nas escolas em prol da implementação da BNCC, envolvendo esforços desses sujeitos. Em minha percepção, esses atores escolares têm estado fortemente implicados - não por convite ou por opção, como muitos gostam de reforçar, mas por demanda e regulação das próprias redes de ensino - no processo compulsório de implementação da BNCC nas escolas das redes estaduais e municipais de Barreiras, Bahia. Quando falo de demandas regulatórias, refiro-me à atualização de traços históricos de sentidos ligados à política da accountability no currículo e na educação, a qual faz referência à buscas por padronizações, controle de eficiência de implementação e de resultados, avaliação da eficiência das ações implementadas, prestação de contas e responsabilização (TAUBMAN, 2009; LOPES; MACEDO, 2011). Há um forte investimento com o intuito de fazer a base "sair do papel" nas escolas da região, reunindo esforços dos atores sociais selecionados para compor, junto a mim, os argumentos deste texto.

Os professores, por um lado, mostram-se figuras principais nesse processo, porque, além de serem os sujeitos diretamente envolvidos pela política da BNCC e suas demandas por reformulação curricular, participam como parceiros na formação inicial dos estudantes de estágio supervisionado dos cursos de licenciatura da região. Aos professores, solicitei que respondessem às seguintes perguntas em um questionário: (i) Em sua opinião, como vem ocorrendo o processo de implementação da BNCC nas escolas estaduais / municipais de Barreiras? (ii) Como você tem percebido os principais êxitos e desafios das ações de articulação da BNCC nas escolas? Qual a sua percepção sobre os maiores pontos de acordo e de resistência que os professores comumente relatam? (iii) Como a implementação da BNCC vem repercutindo em sua prática como professor/professora?

Os estagiários, por outro lado, não passam incólumes aos discursos e demandas que vêm reconfigurando o exercício da docência nesses contextos, e entram em cena neste debate porque o processo de implementação da BNCC, no âmbito dos Estados e Municípios, 
vem produzindo impactos diretos na formação inicial destes sujeitos, na medida em que são convidados, pelas escolas, a apresentarem, em suas propostas de pesquisa e atividades dos/nos estágios, a forma como pretendem trabalhar com as habilidades e competências postas na BNCC, e o modo como irão verificar as aprendizagens. Trata-se de estudantes do curso de Licenciatura em Ciências Biológicas sediado em uma Universidade Federal à qual estou vinculado como docente. A esses sujeitos, solicitei que relatassem sobre suas percepções acerca da implementação da BNCC nas escolas da região, mediante a realização de grupos focais de discussão sobre a BNCC na universidade.

Em síntese, esses registros empíricos formam o material a partir do qual construí alguns posicionamentos a respeito da implementação da BNCC e sua (des)configuração das/ nas redes educativas do Oeste da Bahia. É sempre bom lembrar que as escolhas metodológicas feitas - tanto aqui como em qualquer trabalho - excluíram um tanto de possibilidades outras de leitura desse processo. Acredito, por fim, que o material empírico mobilizado permite uma leitura parcialmente panorâmica da "fase de implementação da BNCC" na região investigada, reunindo visões e posicionamentos de estudantes e professores envolvidos por esta política de readequação / adaptação dos currículos escolares.

\section{ESFORÇOS PARA FAZER A BNCC SAIR DO PAPEL NO OESTE DA BAHIA}

"Precisamos fazer a Base sair do papel, e ela não vai sair sozinha" é uma das inúmeras falas que venho escutando, recentemente, nos corredores de escolas, em seminários sobre a fase de implementação das BNCC nas escolas, em jornadas pedagógicas e tantas outras eventualidades educacionais na região Oeste da Bahia. Fazer a Base sair do papel, nessas falas, tem significado a mobilização dos esforços de vários atores sociais na região com vistas atingir a meta que é "Educar pela Base", e fazê-lo de modo explícito em seus resultados. Do ponto de vista dos estudos pós-estruturais e pós-fundacionais, poderíamos dizer que a tentativa de "fazer sair do papel" pode significar uma aposta no caráter transparente e objetivo da linguagem, isto é, como uma tecnologia cuja única função é a representação direta do signo, a manifestação de sentidos absolutos na significação, a presentificação de algo dado. A questão é que, nessa mesma pauta, não só a função de representação direta é questionada como também se acredita que o signo e o sentido resistem à "realização", se ausentam enquanto presença (LACLAU, 2006; BUTLER; LACLAU; ŽlŽEK, 2004). Em algumas compreensões políticas, essa resistência à realização faz com que os esforços passem a ser cada vez mais incisivos na meta de fazer a Base "virar realidade" (MACEDO, 2019), colocando a norma em constante funcionamento. Assim, a busca 
por fazer a BNCC sair do papel vem forjando, no Oeste da Bahia, certa ambiência regulatória de responsabilização docente no que diz respeito à busca de ações que possibilitem alcançar essa meta, envolvendo esforços de todos nessa empreitada.

A criação de uma ambiência regulatória para fazer a BNCC sair do papel no âmbito das escolas municipais e estaduais da região Oeste da Bahia não se concretiza, no entanto, sem antes produzir um efeito cascata de demandas entre os múltiplos atores sociais envolvidos. Trata-se de uma cascata de demandas com efeitos de avaliação, prestação de contas e responsabilização dos diversos atores sociais envolvidos nesse processo, muitas vezes escamoteada por movimentos de "estudos e discussão" da BNCC no âmbito das "Atividades Complementares" nas escolas. Ao utilizar a metáfora da cascata para tentar interpretar os efeitos regulatórios impostos pela "fase de implementação da BNCC" na região, quero dar destaque ao modo como ela vai produzindo efeitos de controle e responsabilização em múltiplas escalas, um mecanismo característico das políticas administrativas centralizadas cuja principal função é dizer como as coisas devem acontecer nas escolas (LOPES; MACEDO, 2011). A metáfora da cascata, a meu ver, traduz bem esse espírito das políticas administrativas ao provocar efeitos sobre diferentes sujeitos em escalas distintas de atuação, conectando-os em um processo vertical de alinhamento e padronização. A aposta no alinhamento e padronização credencia pensar os processos de "implementação" de uma dada política pela lógica do controle e da transparência entre níveis distintos, sendo estes os mecanismos supostamente capazes de fazer algo "sair do papel" sem desvios ou readequações quaisquer que sejam, marca característica das políticas educacionais e de currículo esteadas na ideia de accountability. Nessa direção, a metáfora da cascata dá conta de traduzir, também, a suposição de transparência e objetividade da linguagem que estrutura políticas curriculares administrativas e centralizadas. A metáfora permite, também, pensar em como esse processo atualiza a ideia de que a linguagem carrega, em si mesma, tudo aquilo que deseja significar, e que o processo de implementação se dá por simples transporte de sentido. É justamente nesse sentido que, buscando compreender o efeito cascata dos discursos regulatórios, trago alguns registros empíricos para compor comigo este texto, articulando diferentes sujeitos e práticas.

Em um dos níveis desta cascata, estão posicionados os estudantes de Licenciatura em Ciências Biológicas com os quais venho trabalhando em minha atuação profissional no Oeste da Bahia. Trata-se de estudantes em vivência de estágios supervisionados, momento no qual encontram-se imersos no cotidiano escolar, em processos de pesquisa de observação e práticas de ensino. Na percepção dos estudantes em formação inicial, é comum o apontamento da necessidade de adaptação / reconfiguração dos planejamentos e atividades de ensino das escolas, em decorrência da exigência da implementação da BNCC: 
Durante as 60 horas percorridas na observação da escola e das aulas no ensino fundamental regular, em uma escola municipal de Barreiras, pude constatar aplicação criteriosa, e sempre cobrada pela secretaria municipal de educação, da BNCC. [...] Notei uma certa dificuldade na elaboração dos planejamentos dos professores referente ao atrelamento das competências da BNCC com o conteúdo a se aplicar nas aulas (pude notar que toda a estrutura dos planos foram alteradas pra incorporar as habilidades da BNCC). 0 que se vê é uma nova adaptação a ser absorvida pelos docentes em suas metodologias. (Estagiário 1).

Em minhas observação, é visivel que as escolas têm praticamente corrido para se adequar às novas regras da BNCC. [...] No entanto, a meu ver, a forma como o conteúdo foi organizado não facilita para que os professores trabalhem essas habilidades, e a aprendizagem dos alunos tornou-se ainda mais fragmentada. [... É notável, ainda, um grau de despreparo da escola tanto em seus aspectos estruturais como do quadro de professores em decorrência da falta de políticas públicas que valorize a implementação da BNCC [...], mesmo que esse modelo de educação não seja exatamente funcional. (Estagiária 2).

Como se trata de um ensino cíclico, às vezes, falta uma sequência na sistematização dos conteúdos. Se, por um lado, é bom, já que o aluno revê o conteúdo e, para o professor, direciona como planejar a aula, por outro lado, pode haver uma frustração em não conseguir alcançar tais habilidades. É importante observar que em algumas escolas não há recurso e infraestrutura que possibilite desenvolver algumas das habilidades. [...] Além de restringir o planejamento, visto que há uma obrigação para que seja trabalhada a BNCC em aula. (Estagiária 3).

[..] Nas escolas de Barreiras, no oeste da Bahia, é perceptivel uma certa dificuldade em passar os conteúdos e atingir as habilidades. Além disso, uma outra dificuldade notória é que os novos livros não possuem os conteúdos sequenciados e específicos para que possam atingir as competências e habilidades. Da mesma forma, nem todos os professores seguem, à risca, os conteúdos da forma lógica e progressiva exigida, assim como o próprio ambiente físico não permite a realização de algumas propostas pela BNCC. Assim, parece algo semelhante a uma lei, com regras e deveres que, na prática, são quase impossiveis de serem realizados. [...] Para além disso, podemos ainda citar que a nova proposta de ensino parece algo mecanizado, com sugestões e códigos de ensino-aprendizagem que mecanizam os alunos e a educação brasileira, sem instigar o poder de interferência e conhecimento do aluno em sala de aula. (Estagiário 4) (informações verbais).

Os depoimentos dos/as estagiários/as apresentam diversos aspectos que podem ser problematizados sobre o processo de implementação da BNCC nas escolas da região. A começar pela observação comum de ausência de infraestrutura necessária para um bom trabalho com a BNCC nas escolas. Em seus relatos, parece haver a constatação de um desencontro entre a proposta pedagógica da BNCC, e os recursos disponíveis aos professores, nas escolas, para fazer a BNCC "sair do papel". 0 que pode ser ainda mais problemático de observar, nesse processo, é a obrigatoriedade colocada pelas secretarias 
de educação para a implementação, sendo que as condições escolares não são postas em questão. Está em curso a reformulação de todos os planejamentos de ensino das escolas baseada nos códigos e habilidades sugeridas pela BNCC para os anos específicos de escolarização, sem, no entanto, haver contrapartida em termos de infraestrutura escolar.

Ao lado desse aspecto, os relatos apontam dificuldades pessoais dos/as estagiários/as e dos/as professores/as supervisores/as em sequenciar conteúdos e "objetos de conhecimento" de modo a atingir as habilidades previstas na BNCC. Constata-se a ausência de orientação (seja da própria política, seja das ações da fase de implementação, seja dos livros didáticos) precisa sobre como sequenciar os conhecimentos e conteúdos trabalhados, de modo a fazer a BNCC "sair do papel" e tornar-se explícita no ensino e na aprendizagem. Ao vivenciarem a ambiência gerada pela BNCC nas escolas e compartilharem experiências formativas com os/as professores/as supervisores/as, os estudantes em formação inicial são levados a responder sobre essas demandas postas para que as políticas "se concretizem" nas escolas. Dessa forma, o planejamento torna-se um terreno de debate em torno da sua melhor disposição, no que diz respeito à eficácia de produção de determinado efeito educativo. Há, assim, um questionamento no que diz respeito à sequência e a lógica do desenvolvimento do ensino e da aprendizagem na BNCC: sobre este ponto, peço que coloquem em suspensão essa discussão, prometendo retomá-la, a seguir, no texto.

Outro aspecto a destacar nos relatos é quanto à percepção de uma restrição no que diz respeito às ações de planejamento docente diante da BNCC. Embora alguns relatos contemplem a ideia de que alguns/as professores/as não seguem, à risca, o que é exigido pela BNCC, há a percepção de uma restrição em uma das atividades principais da atuação docente, o planejamento e a organização da prática de ensino (o que, para alguns/as estagiários/as e professores/as, nem sempre é algo problemático para a atuação profissional, vale destacar). Acredito que este é um dos grandes pontos polêmicos da discussão em torno da BNCC na região - quiçá, no cenário nacional -, e nem sempre adquire um teor crítico em relação à normatização e enrijecimento dos planejamentos. Aliás, em alguns casos, vê-se, nesse gesto da política, uma forma de "alívio" em relação às cobranças e expectativas postas sobre a educação, de modo geral, livrando os/as professores/as do "fardo" da responsabilidade nas decisões curriculares. Um alívio fantasmático, defendo, a produzir forte identificação docente ao gerar um efeito de estabilidade no currículo, fazendo crer no alcance de consenso final em torno da melhor forma de ensinar, o que, possivelmente, diminuirá o peso dos discursos de responsabilização docente acerca dos índices de qualidade do ensino e da educação. Aliás, a responsabilização é, em si mesma, uma estratégia discursiva partícipe na hegemonização da própria BNCC no cenário nacional; uma estratégia da norma e da fantasia de controle para continuar deslocando o poder e produzindo identificações na composição de um imaginário educativo baseado no comprometimento absoluto e exclusivo dos professores sobre os resultados dos estudantes na escolarização (FRANGELLA; DIAS, 2018; MACED0, 2019). 
Na percepção dos/as estagiários/as, o fato de os/as docentes não seguirem à risca o que é exigido pela BNCC significa, em alguma medida, um "apego" ao que vinha sendo feito anteriormente. Se, por um lado, na compreensão de alguns deles, isso pode significar resistência à implementação da política, por outro, pode significar, também, o caráter artificial e mecânico de qualquer política curricular que separa elaboração e implantação de currículo; uma constatação que, há décadas, encontra-se amparada nos estudos de políticas educacionais e de currículo. A aposta na distinção entre produção e implementação curricular, uma tônica forte da BNCC - embora matizada pela ideia de que a BNCC não é o currículo, tal como dito no próprio documento - manifesta, logo de início, uma impossibilidade nos contextos, apontando para a ideia de que mudanças curriculares não acontecem repentinamente, tampouco se mostram eficazes pela via do desperdício das experiências curriculares que vinham sendo praticadas. Com isso, não quero me deixar entender que defendo que o fundamento do currículo está, simplesmente, na tradição e prática docente. Apenas alerto que o fundamento do currículo não se encontra nem "lá" na política da BNCC, nem "cá" no chão das escolas, mas é algo ausente, independente desta polaridade, também ela, artificial.

De modo geral, os depoimentos dos/as estagiários/as realçam diversos aspectos que dificultam a implementação da BNCC na região sem, muitas vezes, questionar a necessidade, em si, de uma base curricular para o ensino - a meu ver, a parte mais importante da discussão. Imersos nesses espaços e também demandados quanto à "implementação" da BNCC em suas atividades inicias de ensino, os/as estudantes em formação inicial apresentam preocupações que os fazem pensar ser improvável questionar o próprio valor educacional de uma política cuja função é a determinação da identidade alheia. Fazem-nos considerar inevitável a aplicação da BNCC, deixando, muitas vezes, de lado, a reflexão sobre como a identidade e a criação singular de conhecimento pode ser "solapada quando limitada a respostas a perguntas de outras pessoas, quando é apenas um meio para alcançar objetivos predeterminados." (PINAR, 2012, p. 161). Ao mesmo tempo, por meio dos seus relatos, podem nos fazer pensar em como a BNCC, por ser um universal que se quer absoluto ao definir o que é essencial à todos os currículos e escolas, pode estar impondo restrições severas aos múltiplos contextos e espaços educacionais, na medida em que coloca a si mesma fora de qualquer possibilidade de debate e reformulação em reposta às demandas singulares desses mesmos contextos, extirpando mecanicamente práticas e experiências curriculares em curso, em nome de um pacto hermenêutico curricular que se quer absoluto e universal, para todos.

Em outro patamar desta cascata de efeitos regulatórios, encontram-se posicionados/as os/as professores/as das redes de ensino do Oeste da Bahia. Tal como o próprio documento, a BNCC normatiza e "define o conjunto orgânico e progressivo de aprendizagens essenciais que todos os alunos devem desenvolver ao longo das etapas e modalidades da Educação Básica." (BRASIL, 2018, p. 7). Ao normatizar e definir, de modo vertical, a BNCC acaba por tentar substituir, mecanicamente, experiências e práticas curriculares em 
curso nas redes de ensino, como se já não se fizesse currículo nesses espaços, gerando, no corpo docente das escolas, forte demanda por formação. Em seus relatos, os/as professores/as apontam vários desafios e aspectos regulatórios sobre a implementação da BNCC no Oeste da Bahia:

A implementação vem ocorrendo de uma forma que já foi estabelecida pela Secretaria Municipal de Educação com os objetos de conhecimento já prontos e que os professores devem seguir, e também com as habilidades. [...] Alguns professores tiveram alguma forma de resistência pelo fato de alguns conteúdos precisarem ser pesquisados sem recurso, pois não tem no livro didático. Com a implementação da BNCC na escola, houve uma grande melhoria, pois acho que os conteúdos são bastante interessantes e tem uma sequência mais lógica, os alunos de ciências começam a ver a parte de química e fisica das ciências naturais em todos os anos, não fica vendo somente no $9^{\circ}$ ano. (Professora 1).

Nossa escola discutiu a BNCC durante a $1^{a}$ e a $2^{a}$ jornadas pedagógicas do ano de 2019. [...] As discussões não são aprofundadas, pois teríamos que ter um tempo mais longo de discussões. As Atividades Complementares que são realizadas por articuladores de área em um dia da semana, tem uma demanda de organização de projetos a serem realizados na escola de acordo com a programação da Secretaria de Educação da Bahia, ficando um tempo limitado para discussões da BNCC. Nesse sentido, nossas discussões, por enquanto, são incipientes. Existem professores que não estão dispostos à discussão, mesmo porque não acreditam que as propostas da BNCC possam se concretizar na íntegra como estão no documento. Pelo pouco que discutimos, estamos repensando nossa forma de conduzir o processo de ensino e aprendizagem para podermos criar um espaço mais condizente com as propostas da BNCC. (Professora 2).

A implementação da BNCC nas escolas tem ocorrido de forma gradual, sendo que depende da disponibilidade técnica dos órgãos governamentais das redes estaduais e municipais. A escola tem proporcionado momentos de estudo da legislação durante a jornada pedagógica, onde foi discutido o processo de avaliação e implementação dos itinerários formativos. [...] Temos como ação positiva o estudo da legislação. Quanto às dificuldades, pode-se apontar a falta de infraestrutura nas escolas. (Professora 3).

[...] A implementação da BNCC está ocorrendo gradualmente ao longo do ano letivo, especialmente nas escolas estaduais, como exemplo, é possivel citar o desenvolvimento de oficinas e instruções pedagógicas com o apoio do coordenador(a) da escola, e simulados que abrangem diversas áreas do conhecimento com o objetivo de preparação dos alunos. 0 NTE (Núcleo Territorial de Educação) envia questionários e busca acompanhar o desenvolvimento do processo de implementação, sendo que tal discussão é constante em atividades curriculares e conselhos de classe. [...] Os desafios são muitos especialmente relacionados ao corpo docente, pois algumas práticas ainda são bastante tradicionais, com métodos pouco inovadores. Como agravante, não temos suporte adequado na corrida para tal implementação. A resistência ao novo é grande, inovar é sempre dificil, sem $\mathrm{o}$ apoio e o auxilio adequado se torna ainda mais dificil. Os desafios da 
implementação da BNCC são percebidos especialmente pelo corpo docente, que precisam alinhar a sua prática pedagógica e metodologias com os objetivos da BNCC. (Professora 4).

A BNCC nas escolas estaduais de Barreiras ainda está em processo de discussão de forma restrita. Discussões ocorreram apenas na jornada pedagógica no início do ano letivo. [...] 0 objetivo da BNCC é viabilizar um trabalho pedagógico articulado, contextualizado e de efetivo acompanhamento da aprendizagem dos alunos. No entanto, no contexto escolar atual, o processo de acompanhamento efetivo não é viabilizado. [...] É necessário viabilizar momentos de discussão e estudo para melhor compreensão, e desenvolvimento de ações segundo a BNCC. (Professora 5).

A implantação da BNCC é um fato! Porém, carece de formação e mais discussão nas escolas de Barreiras. 0 objetivo da BNCC é válido, pertinente, porém há muito que se investir em formação, recursos, estruturas físicas e pedagógicas de suporte para os profissionais envolvidos. Os professores reclamam muito da quantidade de conteúdo. Relacionar habilidade / competência e operacionalização do objeto de conhecimento é um desafio. (Professor 6).

A BNCC surgiu sem muita discussão, quase que uma imposição, sem tempo hábil para analisar e aplicar. Os êxitos acredito que sejam gradativos, ano após ano, pois, os próprios discentes sentem também o trabalho diferente e estão procurando se adaptar. A resistência seria à organização dos conteúdos. Ou seja, aquilo que é básico, prévio, aparece posteriormente. [...] A grande mudança nos currículos nos impossibilitou de conduzir o trabalho com tranquilidade (sem livro), recorrendo a autores diversos e tentando adaptar ao nível de entendimento do aluno e ao ano. (Professora 7) (informações verbais).

Começo ponderando sobre a ideia de "lógica", sequenciamento e organização dos objetos de conhecimento presente nos relatos, pedindo que retirem da suspensão a discussão anteriormente citada sobre este aspecto. Primeiro, talvez, seja preciso destacar o quão problemático pode ser a BNCC achar que não define currículo e, ao mesmo tempo, reduzir o trabalho dos/as professores/as unicamente à organização didática e busca por sequenciamentos ideias que façam as aprendizagens acontecerem, responsabilizando, sobremaneira, a figura do professor e mecanizando a docência. Restringir a ação docente à busca por formas de articulação entre competências, habilidades e objetos de conhecimento, previamente definidos, para fins de produção de efeitos educacionais, também eles, previamente delineados, além de reduzir a educação e a escola ao ensino de um conjunto de conteúdo, tem forjado uma ambiência de regulação e controle das ações docentes baseada na política do accountability. Isso sem falar na redução do planejamento ao etapismo tecnicista, estagnando sua dimensão precipuamente política. Essas características técnico-eficientistas se expressam, ainda, no vínculo explícito e na importância exacerbada conferida aos processos avaliativos na escola, configurados como instrumentos capazes de mensurar e certificar o desenvolvimento 
das referidas habilidades e competências. Apesar de ser uma simplificação restritiva da docência, tanto nos relatos dos professores como dos estagiários, a implementação da BNCC mostra-se, desde o início, permeada por questionamentos em relação à sua proposta de organização progressiva das aprendizagens com os conhecimentos, sugerindo que a norma, ao ser colocada em funcionamento, produz suas próprias ambivalências, inclusões e exclusões. Mais do que isso, a normatividade curricular colocada em curso pela BNCC, por mais absoluta e transparente que almeje ser, desperta, ainda assim, debates sobre qual a "melhor lógica" de organização dos conteúdos, sugerindo que os desacordos, antagonismos e a própria diferença em relação ao entendimento de "lógica progressiva de aprendizagem" (BRASIL, 2018) estão sempre a emergir, mostrando-se como processos resistentes a fixações. A restrição imposta pela norma permanece sendo habitada pelas disputas discursivas em torno da "organização" dos objetos de conhecimento. As disputas discursivas parecem, portanto, não cessar, mesmo que constrangidas desde a forma como a norma é fixada no texto, até às expectativas de aprendizagem projetadas sobre os professores, fazendo a ânsia por transparência da BNCC sucumbir aos jogos de linguagem.

Outro aspecto a destacar, fortemente imbricado às discussões acima, é que: como a promessa de uma educação mediada por sequenciamento de objetos de conhecimento, supostamente capazes de produzir efeitos educacionais inequívocos (habilidades, competências), é algo que, possivelmente, a BNCC - e, quiçá, qualquer política de currículo jamais conseguirá cumprir, demandas por "mais estudo", "aprofundamento", "acompanhamento" e "mais formação" acabam por manifestarem-se, fortemente, nos relatos dos docentes. Tratase de demandas que, nos relatos e debates, manifestam-se, quase que exclusivamente, vinculadas ao dever de bem implementar e, assim, garantir as aprendizagens. É preciso, no entanto, problematizar essa ânsia por formação e acompanhamento: em que medida as ações de formação continuada serão capazes de garantir um entendimento completo - que se quer único, transparente - da BNCC e, consequentemente, uma implementação direta, com garantia absoluta das aprendizagens? Em muitos aspectos, os discursos da necessidade de formação são alimentados pelos da necessidade de garantia das aprendizagens e da inovação no currículo, tornando-se, eles mesmos, seus próprios fundamentos. Uma estratégia discursiva difícil de problematizar, porque vincula, de modo determinista, processos que apresentam alguma relação: educação - ensino - aprendizagem. Amplifica-se, assim, nos professores, o desejo e a necessidade de subsídio formativo uma vez que, seria essa, a única via de acesso a uma implementação da BNCC capaz de garantir a aprendizagem, ficando intocada a linguagem do cálculo e da responsabilização docente.

Ponto pacífico em praticamente todos os relatos, a ausência de infraestrutura, tanto física como pedagógica, é apontada como um dos grandes entraves presentes no processo de implementação da BNCC. A ausência de livros didáticos é um fator importante apontado nesse processo, mostrando que, na região 0este, esse material didático é, ainda, uma 
forte expressão do currículo escolar, sobretudo pela ausência de outros meios de pesquisa nas escolas. É importante destacar, no entanto, que este não é um entrave exclusivo de uma política curricular como a produzida pela BNCC, mas de políticas verticais e centralizadas cujo papel de representação totalitária daquilo que julga conhecer acaba por manifestar forte desprezo pelas condições contextuais de implementação dos/nos múltiplos espaços e tempos educacionais. Ball, Maguire e Braun (2016) têm, há décadas, reiterado a tese de que políticas educacionais - incluindo aí, as de currículo - que desprezam fatores como disponibilidade de recursos e tempo, disponibilidade materiais, capacidade das escolas e das redes em recrutar e reter professores nas escolas, formação contínua dos docentes, entre outros, tendem a fracassar por não compreenderem as escolas como locais únicos de atuação das políticas. É essa compreensão complexa dos espaços e tempos educacionais que afasta qualquer possibilidade de que uma dada política seja, simples e diretamente, reproduzida nas escolas. Pondero que, nessa discussão, é, também, preciso ir além da denúncia sobre ausências que afligem os docentes e as escolas e, consequentemente, a implementação da BNCC, no sentido de questionar a produtividade de racionalidades que almejam produzir identidades únicas para a docência e o currículo. Trata-se de projeções antecipadas de identidades a serem assumida antes mesmo do próprio exercício da docência e do acontecimento curricular nas escolas, vinculando, também, nesse processo, as identidades dos estudantes. Ao ler os relatos dos docentes e cotejá-los com as teses defendidas nos estudos em políticas educacionais, podemos questionar: mostra-se viável e produtivo descartar toda a experiência e as identificações com aquilo que já se faz nas escolas, em nome da "inovação adaptacionista" imposta pela BNCC?

0 debate sobre o caráter inicial da implementação é outro importante aspecto a ser debatido. Em muitos casos, essa discussão vincula-se ao debate sobre o "apego docente" àquilo que, julgam alguns, é tradicional nas práticas escolares, e resiste a mudanças e inovações. Acredito que o imbróglio tradição $x$ inovação nos oportuniza um debate, comum no campo das políticas educacionais, sobre a artificialidade e a verticalidade imposta por políticas que pretendem reconfigurar o chão das escolas sem escutar, devidamente, os docentes e a docência exercida, e sem viabilizar tomadas de decisões curriculares nesses espaços. Ao buscar substituir os currículos e as experiências escolares, a BNCC trabalha no sentido de alinhar identidades de prática, metodologias e avaliações numa tentativa de fixação absoluta, buscando estagnar o processo político constitutivo de identidades, suprimindo espaços para decisões outras.

Por fim, apesar de não trazer relatos desses sujeitos, os articuladores de área vêm se mostrando figuras relevantes nesse processo, porque vêm atuando diretamente em Atividades Complementares (AC) nas escolas enquanto difusores das questões conceituais e curriculares postas na BNCC, ou seja, vêm atuando como agentes que recebem os materiais de suporte para implementação e buscam fazer a formação continuada na escola 
com o intuito de aprimorar, junto aos professores, a compreensão do documento da BNCC visando a sua implementação. Em muitos casos, os articuladores de área da região Oeste da Bahia têm sido os próprios professores e coordenadores das redes de ensino, alguns deles prioritariamente eleitos por apresentarem pós-graduação nas áreas específicas que compõem a BNCC (Linguagens, Ciências da Natureza; Ciências Humanas e Sociais, Matemática). Com o apoio dos materiais e guias de implementação, disponibilizados tanto pelo Ministério da Educação (MEC) como pelas Secretarias de Educação, os articuladores de área vêm atuando nos momentos de AC das escolas, no intuito de estudar e discutir com os professores a proposta curricular da BNCC, com o objetivo de fazê-los "conhecer a fundo" o documento. Na condição de articuladores de áreas, os professores atuantes alegam, muitas vezes, eles mesmos, não terem tido o tempo suficiente para estudar a BNCC e as discussões que têm sido realizadas sobre a sua proposta formativa para o Ensino Fundamental e Médio. Apontam, também, o movimento de imposição das Secretarias de Educação em fazer conhecer a BNCC nas escolas, motivo pelo qual foram, muitas vezes sem escolha, eleitos para atuarem como formadores da Base.

\section{CONSIDERAÇÕES FINAIS}

Enquanto escrevo e reviso este trabalho, o CNE lança o texto orientador das Diretrizes Curriculares Nacionais da Base Nacional Comum (BNC) da Formação Inicial e Continuada de Professores, ${ }^{5}$ mostrando que a irradiação de efeitos hegemônicos das políticas centralizadoras continua se alastrando, rapidamente, em seus esforços e objetivos de padronização e alinhamento curricular. Mais desafiante ainda é perceber, mediante os relatos aqui discutidos, que, independente da BNC da formação docente estar sendo proposta, a BNCC já vem ressoando com força na formação inicial e continuada dos professores, forjando adaptações curriculares nos mais distintos espaços educacionais do país.

Embora a Base aí esteja e, com ela, toda racionalidade fundacionista e antidemocrática do ponto de vista curricular, o que fica, a meu ver, explícito em seu processo de implementação no contexto educacional do Oeste da Bahia é que as disputas pelo sentido do currículo jamais cessarão. Enquanto houver "apego" ao que vinha sendo feito, enquanto houver desacordos e disputas pela forma como "sequenciar objetos de conhecimento" nos planejamentos, enquanto houver disputa pela "lógica de organização dos conhecimentos" no currículo, enquanto houver readequações às condições escolares, enquanto houver Disponivel em: http://portal.mec.gov.br/index.php?option=com_docman\&view=download\&alias=124721-texto-referencia-
formacao-de-professores\&category_slug=setembro-2019\&/temid=30192. Acesso em: 5 nov. 2019. 
questionamentos à imposição da norma e à capacidade da BNCC em se concretizar nas escolas, enfim, enquanto houver linguagem, a política jamais cessará. Embora essas dimensões não representem um espaço mais livre e aberto de participação docente na elaboração e planejamento curricular tal como desejamos, é importante perceber que há sempre uma disputa de sentido em curso no momento em que políticas são endereçadas às escolas, há sempre um complexo processo que envolve adequação, negociação, resistência, facilidades e dificuldades de interpretação e atuação (BALL; MAGUIRE; BROWN, 2016; LOPES, 2015a, 2015b), entre outros, que fazem com que a possibilidade de transmissão harmônica de um dado sentido, que se quer inegociável, manifeste-se de forma precária, finita. Se a Base parece agigantar-se como princípio de certeza curricular no Oeste da Bahia, isso não significa que, no processo de implementação, a regulação e a coerção que ela impõe não sejam questionadas, muito menos que a sua chegada seja harmônica e sem desajustes quaisquer que sejam, facultando pensar que sua ânsia fundacional por identidade sólida, a nível nacional, vai se desfazendo em meio às interpretações contextuais e ao "apego" a todas as experiências curriculares e de aprendizagem que ela almeja extirpar e substituir.

Nesse contexto, penso que lutar contra a hegemonia da BNCC - possibilitando e viabilizando articulações e hegemonias outras, cuja pauta e agenda deem destaque a ações e políticas menos centralizadoras e deterministas - pode ser colocar em evidência e amplificar os antagonismos, desacordos pedagógicos, dificuldades interpretativas e resistências, quaisquer que sejam. Talvez, uma das formas de fazer isso seja por meio da explicitação, cotidiana, na formação docente, de como a BNCC tenta nos desresponsabilizar de um dos principais compromissos ético-políticos da docência: o planejamento curricular e didático de nossas ações educativas, nos múltiplos espaços e tempos educacionais. Isso significa atuar na formação inicial e continuada de professores debatendo, deixando sempre em aberto, e colocando em evidência as múltiplas referências nacionais que já foram produzidas ao longo da história da política de currículo nacional, e que podem subsidiar - e não substituir - as discussões sobre o planejamento do currículo escolar, nos mais variados contextos. Significa, portanto, dar atenção ao nosso protagonismo docente em nossas atuações formativas, sem deixar que outros estejam sempre a nos dizer para onde devemos ir quando o assunto é formação e currículo escolar. Como procurei argumentar neste trabalho, se a figura do fundamento que busca sustentar a BNCC como o melhor caminho a seguir é um abismo, isso significa que podemos apostar em nossas criações curriculares nas escolas, recuperando nosso protagonismo docente nas decisões curriculares. Um protagonismo recuperado não como sujeitos fortes colidindo com a norma, mas como sujeitos que entenderam que decisões sem garantias sempre estão a ser tomadas quando o assunto é currículo e formação, e que faz parte da nossa responsabilidade e compromisso ético e profissional, assumir essa tarefa nas escolas. Buscar assumir a recuperação desse protagonismo significa tentar frear, em alguma medida, a ânsia das políticas centralizadas em sempre querer dizer ao professor 
o que ele deve fazer - por mais interessantes e pedagogicamente consistentes que essas orientações possam ser, e por mais competentes que os formuladores também o sejam para atingir determinadas finalidades sociais, sendo que, nem mesmo as políticas nem as finalidades - ambas sempre genéricas, verticais e abstratas -, são colocadas em debate.

Por fim, enquanto a Base e todos os discursos e agente sociais a ela vinculados podem nos fazer pensar que ela é a melhor intuição curricular, a melhor decisão política, o melhor caminho a seguir na formação escolar, acredito que, mediante os relatos aqui compartilhados sobre o processo de implementação no Oeste da Bahia, podemos conceber que a racionalidade colonial e normativa de controle que ela - a Base - manifesta, permanece sendo habitada pelo imponderável (MACED0, 2014) e tudo mais que torna o cotidiano um espaço caótico criativo, sujeitando-a a múltiplos níveis de tradução e disseminação de sentidos. Com isso não quero dizer que esses desajustes são, necessariamente, bons - e isso não está em discussão neste texto. 0 foco é a ideia de que é possível a implementação direta e inequívoca da BNCC. Por fim, em meio ao agito forte das incessantes ondas desse mar de regulação e controle, é na pauta pós-fundacional dos estudos da política e do currículo que busco amparo e carrego a confiança na ideia de que, por maiores que sejam as tentativas de regulação impostas pela BNCC, ela será incapaz de erradicar, de uma vez por todas, a indeterminação última do/no momento instituinte de qualquer decisão curricular.

\section{REFERÊNCIAS}

BALL, S. J.; MAGUIRE, M.; BRAUN, A. Como as escolas fazem as políticas: atuação em escolas secundárias. Ponta Grossa: Editora UEPG, 2016.

BHABHA, H. K. 0 local da cultura. Belo Horizonte: Ed. UFMG, 2013.

BIESTA, G. Boa educação na era da mensuração. Cadernos de Pesquisa, v. 42, n. 147, p. 808-825, dez. 2012. DOl: https://dx.doi.org/10.1590/S0100-15742012000300009.

BIESTA, G. Para além da aprendizagem: educação democrática para um futuro humano. Belo Horizonte: Autêntica, 2013.

BIESTA, G. The beautiful risk of education. London: Routledge, 2016.

BRASIL. Ministério da Educação. Base Nacional Comum Curricular: educação é a base. Ensino Médio. Brasilia, DF: MEC, 2018.

BUTLER, J.; LACLAU, E.; ŽZZŽEK, S. Contingencia, hegemonía, universalidad: diálogos contemporáneos en la izquierda. Buenos Aires: Fondo de Cultura Económica de Argentina, 2004. 
BUTLER, J. Quadros de guerra: quando a vida é passível de luto? Rio de Janeiro: Civilização Brasileira, 2017.

BUTLER, J. Relatar a si mesmo: crítica da violência ética. Belo Horizonte: Autêntica, 2015.

CUNHA, E. V. R. Cultura, contexto e a impossibilidade de uma unidade essencial para o currículo. Currículo sem Fronteiras, v. 15, n. 3, p. 575-587, 2015. Disponivel em: https://www.curriculosemfronteiras. org/vol15iss3articles/cunha.pdf. Acesso em: 10 fev. 2020.

FRANGELLA, R. C. P.; DIAS, R. E. Os Sentidos de Docência na BNCC: efeitos para o currículo da educação básica e da formação/atuação de professores. Educação Unisinos, v. 22, n. 1, p. 7-15, jan./mar. 2018. D0l: https://dx.doi.org/10.4013/edu.2018.221.01.

GLYNOS, J.; HOWARTH, D. Critical explanation in social science: a logics approach. Swiss Journal of Sociology, v. 34, n. 1, p. 5-35, 2008. Disponivel em: https://www.researchgate.net/profile/Jason_Glynos/publication/328145174_Critical_Explanation_in_Social_Science_a_Logics_Approach/ links/5bbb4f2c4585159e8d8c32c3/Critical-Explanation-in-Social-Science-a-Logics-Approach.pdf. Acesso em: 10 fev. 2020.

LACLAU, E. Ideology and post-Marxism. Journal of Political ldeologies, v. 11, n. 2, p. 103-114, 2006. D0I: https://doi.org/10.1080/13569310600687882.

LACLAU, E. Los fundamentos retóricos de la sociedad. Buenos Aires: Fondo de Cultura Económica, 2014.

LACLAU, E.; MOUFFE, C. Hegemonia e estratégia socialista: por uma política democrática radical. São Paulo: Intermeios, 2015.

LOPES, A. C.; MACEDO, E. Teorias de Currículo. São Paulo: Cortez, 2011.

LOPES, A. C. Normatividade e Intervenção política: em defesa de um investimento radical. In: LOPES, A. C.; MENDONÇA, D. A Teoria do Discurso de Ernesto Laclau: ensaios críticos e entrevistas. São Paulo: Annablume, 2015a. p. 117-147.

LOPES, A. C. Políticas de Currículo em um enfoque discursivo: notas de pesquisa. In: LOPES, A. C.; OLIVEIRA, A. L; OLIVEIRA, G. G. A teoria do discurso na pesquisa em educação. Recife: Ed. UFPE, 2018. p. १३3-१६७.

LOPES, A. C. Por um currículo sem fundamentos. Linhas Críticas, v. 21, n. 45, p. 445-466, maio/ago. 2015b. Disponivel em http://periodicos.unb.br/index.php/linhascriticas/article/view/16735. Acesso em: 10 fev. 2020.

MACEDO, E. Base Nacional Curricular Comum: novas formas de sociabilidade produzindo sentidos para educação. Revista E-Curriculum, v. 12, n. 3, p. 1530-1555, out./dez. 2014. Disponivel em http://revistas. pucsp.br/index.php/curriculum/article/view/21666. Acesso em: 10 fev. 2020. 
MACEDO, E. Fazendo a base virar realidade: competências e o germe da comparação. Retratos da Escola, v. 13, n. 25, p. 39-58, jan./maio 2019. D0l: https://dx.doi.org/10.22420/rde.v13i25.967.

PINAR, W. F. A equivocada educação do público nos Estados Unidos. In: GARCIA, R. L.; MOREIRA, A. F. B. (org.). Currículo na contemporaneidade: incertezas e desafios. 4. ed. São Paulo: Cortez, 2012. p. 153-173.

TAUBMAN, P. Teaching by numbers: deconstructing the discourse of standards and accountability in education. New York: Routledge, 2009. Disponivel em: https://www.researchgate.net/file.PostFileLoader.htmli id=567ae7f7614325f5548b457c\&assetKey=AS\%3A309891711864833\%401450895349621. Acesso em: 10 fev. 2020.

VATTIMO, G. As aventuras da diferença: o que significa pensar depois de Heidegger e Nietzsche. Lisboa: Edições 70, 1980.

VATTIMO, G. 0 fim da modernidade: nilismo e hermenêutica na cultura pós-moderna. Tradução: Eduardo Brandão. 2. ed. São Paulo: Martins Fontes, 2007.

Endereço para correspondência: Rua Professor José Seabra de Lemos, 316, Recanto dos Pássaros, Barreiras, Bahia, Brasil; cpjunior@ufob.edu.br 


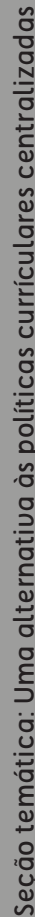

